\title{
Profile of the Patient with Fracture of Proximal Femur in a Regional Trauma Service
}

\section{Edir Soccol Junior ${ }^{1 *}$, Mauro Remulo Grinfelder Brunel Rodrigues ${ }^{2}$, Laura Maria Voss Spricigo ${ }^{3}$, Neri Machado Junior ${ }^{4}$, Fabio Cavali ${ }^{4}$, Fernando Soccol ${ }^{4}$, Haiana Cavalheiro ${ }^{4}$ and Ronan Bertinatto ${ }^{4}$}

${ }^{1}$ Department of Orthopedics and Traumatology, Department of Hip and Pelvic

Surgery of the Pato Branco Polyclinical Institute, Paraná, Brazil

${ }^{2}$ Fellowship in Trauma and Reconstructive Surgery, Department of Orthopedics

and Traumatology of the Governador Celso Ramos Hospital, Florianópolis, Santa

Catarina, Brazil

${ }^{3}$ Medicine Student from the University Center of Pato Branco, Pato Branco, Paraná,

Brazil

${ }^{4}$ Department of Orthopedics and Traumatology of the Pato Branco Polyclinical

Institute, Paraná, Brazil

*Corresponding Author: Edir Soccol Junior, Department of Orthopedics and Traumatology, Department of Hip and Pelvic Surgery of the Pato Branco Polyclinical Institute, Paraná, Brazil.
Received: July 24, 2021

Published: August 04, 2021

(C) All rights are reserved by Edir Soccol

Junior., et al.

\section{Abstract}

With the increase in the elderly population, there is an increasing concern about health problems in this age group. Studies reveal that the mortality of elderly people with fractures of the proximal femur varies from $14 \%$ to $36 \%$, with osteoporosis as the main contributor. The mechanism of fracture of the proximal third of the femur most reported in the literature is falling from their own height, with risk factors being the female gender, presence of chronic diseases, history of falls and environments with inadequate surfaces. In order to describe and analyze the epidemiological profile of the patient diagnosed with a proximal femur fracture, an analysis of medical records was made, at a regional reference service for orthopedic trauma, of patients whose main diagnosis was a fracture of the proximal femur during the period of March 2018 to March 2020. The variables analyzed were sex, age, fracture topography, fracture mechanism, associated comorbidities, level of ambulation (pre and postoperative) and chosen treatment. With a sample of 197 patients, 131 were female and 66 were male, with an average age of 76 years. The most prevalent comorbidity was Systemic Arterial Hypertension. The topography most found was Transtrochanteric Tronzo 3B. In the preoperative phase, most patients were community walkers without assistance, and in the postoperative phase, home walkers with assistance predominated. The most used treatment was the Cephalomedullary Nail. Based on this, the present study made it possible to add knowledge about the epidemiology of proximal femur fracture, informing health professionals about the profile of the patient susceptible to this trauma, enabling the establishment of interventional actions to avoid fracture or minimize its risks.

Keywords: Epidemiology; Femoral Fractures; Hip Fractures

Citation: Edir Soccol Junior., et al. "Profile of the Patient with Fracture of Proximal Femur in a Regional Trauma Service". Acta Scientific Orthopaedics 4.9 (2021): 16-22. 


\section{Introduction}

The aging population is already a reality observed in our country. ${ }^{1}$ According to the World Health Organization (WHO), the individual who is 60 years of age or older is considered to be elderly $[2,3]$. As this portion of the population growth rapidly, a growing concern about the health problems of this age group, especially those related to the decline in organic functions and the increase in degenerative diseases, is emerging $[1,2]$.

In this context, osteoporosis gains importance, since it is a disease characterized by changes in bone microarchitecture, being one of the main responsible for the occurrence of low impact fractures [4]. In the group of osteoporotic fractures we can mention the Proximal Femur Fractures (PFF), which due to its complications, has become a serious public health problem in Western societies [5].

Among the elderly, PFF are most often caused by low-energy trauma, with falls from height being the main cause of this type of fracture [1]. Considered for having a multifactorial etiology, the literature brings some risk factors directly related to the origin of the falls, being: female gender; advanced age; dizziness; consumption of varied continuous-use medication; cognitive decline; presence of chronic diseases; worse physical performance; history of falls; locations with slippery surfaces and insufficient lighting [6].

The PFF group includes Femoral Neck Fractures, Transtrochanteric Fractures and Subtrochanteric Fractures [1,7,8]. Femoral neck fractures predominate in the elderly between the seventh and eighth decade of life. Transtrochanteric fractures predominate in the elderly over 80 years of age [7]. More than $98 \%$ of the cases of PFF are treated surgically, even though there is no consensus on the best surgical technique for each type of PFF [1,9]. It is recommended conservative treatment for cases of incomplete fractures or fractures without deviation, in cases of bedridden patients or without walking conditions and also for those elderly with comorbidities that contraindicate the operative process [10].

The time of surgical approach is closely correlated with the evolution of the patient, and delays in the operation can compromise the patient's functional recovery [11]. In general, it is prioritized that surgical correction is performed within 48 hours after the fracture $[8,11]$. However, it is necessary that the patient be clini- cally stabilized before the procedure to reduce the risks and postoperative complications [11].

It is known about the difficulty of treating hip fractures in patients with low bone density. Internal fixation of PFF can result in failure, taking the patient to prolonged periods of bed rest, as well as restricted walking [12]. This can lead to multiple severe complications, such as deep venous thrombosis, pulmonary embolism, surgical site infection, acute renal failure, pressure ulcers, stroke and adverse events recorded from delirium [13].

PFF significantly increases the morbidity and mortality of patients, in addition to generating a decrease in their quality of life, since functional impairment is one of the greatest negative impacts on the patient's life $[1,5]$. Epidemiological studies reveal that within one year mortality of elderly people with fractures of the proximal femur varies from $14 \%$ to $36 \%$. Of those who survive, only $50 \%$ to $65 \%$ of patients return to functional recovery from previous activities [9]. Furthermore, less than $50 \%$ of patients can walk without assistance, and only $40 \%$ can perform activities of daily living independently [14].

Mobility problems are common and expected consequences for fractures of the proximal third of the femur [14]. The reduction of movement is related to the lack of muscle strength and power in the postoperative period of patients, which can lead to a decrease in the ability to ambulate, making it more susceptible to further falls. Studies show that the chances of a new fracture are six to twenty times greater than the first, within the first year of recovery. Mainly, attention is paid to contralateral hip fractures to the initial fracture $[14,15]$.

Another relevant point is the coexisting diseases in patients who undergo PFF, especially those related to complications and mortality of the patient after the fracture. Among the most prevalent previous diseases at the time of the trauma are: heart disease, stroke, kidney disease, lung disease and diabetes mellitus. Still, the greater the amount of comorbidities present, the greater the chances of death $[16,17]$.

Owing to the high degree of morbidity and mortality, PFF generate high economic costs for health systems, due to the need for hospitalization, surgical treatments and intensive care in the postoperative period [18]. In Brazil it is estimated that the direct costs 
of treating hip fractures in the elderly range from $\mathrm{R} \$ 1,700.00$ to $\mathrm{R} \$$ $24,000.00$ [19].

Thus, given the high incidence of PFF, related to population aging, in addition to the high rates of mortality and postoperative complications, added to the economic costs of treatment, it is relevant to investigate the profile of the patient who has PFF, in order to establish points of intervention to prevent this type of fracture and ensure the promotion of care for this population.

\section{Objective of the Study}

Describe and analyze the epidemiological profile of the patient diagnosed with a proximal femur fracture in a regional reference service in orthopedic trauma, analyzing the variables associated with the fracture of the proximal femur, such as sex, age, fracture topography, fracture mechanism, associated comorbidities, level of ambulation (pre and postoperative) and chosen treatment.

\section{Methods}

Ethics committee

The records of a hospital in the Southwest of Paraná, a reference in orthopedic trauma, were consulted with further analysis, obtaining the information through authorization by the health institution involved, by signing the Institution Consent Form. The research project was submitted for approval by the Research Ethics Committee of the Centro Universitário de Pato Branco - PR. As this is a retrospective study, the Informed Consent Form was waived.

\section{Data collection}

An epidemiological and retrospective study was carried out by analyzing the medical records of patients whose main diagnosis was a fracture of the proximal femur, from March 2018 to March 2020, in a hospital in southwest Paraná, a reference in orthopedics trauma. The variables analyzed were sex, age, fracture topography, fracture mechanism, associated comorbidities, level of ambulation (pre and postoperative) and chosen treatment. In addition, orthopedic fracture classifications were used to better outline the epidemiological profile. For Transtrochanteric fractures, the Tronzo classification was used (1. without deviation; 2 . complete with deviation; 3A. comminution of the large trochanter; 3B. detachment of the small trochanter; 4 . comminution of the posterior wall; 5 . inverted line). For Femoral Neck fractures, the Garden classification was used (1. incomplete or impacted; 2 . complete without de- viation; 3. complete with partial deviation; 4. complete with total deviation and realignment of bone trabeculae). For Subtrochanteric fractures, the Seinsheimer classification was used (1. deviations smaller than $2 \mathrm{~mm}$; $2 \mathrm{~A}$. transverse in two fragments; $2 \mathrm{~B}$. two parts, with a minor trochanter incorporated into the proximal fragment; 2C. two parts, with a minor trochanter incorporated into the distal fragment; $3 \mathrm{~A}$. three parts, with minor trochanter detached from the proximal fragment; 3B. three parts, with minor trochanter incorporated into the proximal fragment - butterfly wing; 4. comminuted in four or more fragments, 5 . sub-intertrochanteric, with a feature that extends to the greater trochanter).

The data from the medical records were collected with the aid of the Data Collection Form, and were analyzed using central variability trend measures and graphic devices. The identification of the patient in the form was made by initials and only the researchers used it for statistical purposes, with no further identification of the data. After collection, the data were stored in a numbered archive in order to initiate the confidentiality procedure.

The inclusion criterion considered patients with a diagnosis of proximal femur fracture, of both sexes, admitted to the institution from March 2018 to March 2020. Medical records that, for some reason, did not contain the minimum information necessary for filling in the variables listed for data collection, were excluded.

\section{Statistical analysis}

The data were analyzed with descriptive statistics (frequency distribution) in the SPSS for Windows software version 21.0 and presented in the form of graphs.

\section{Results}

197 patients were included, of whom 131 are female and 66 are male. The average age was 76 years, and the range was 19 to 96 years. Graph 1 and 2 represent the percentages of the sample characterization data.

The PFF among of patients samples were varied, the most prominent cases being: Transtrochanteric Tronzo 3B with 45 cases and Femoral Neck Garden 3 with 29 cases, followed by Transtrochanteric Tronzo 3A ( $n=25)$, Transtrochanteric Tronzo $2(n=22)$ and Femoral Neck Garden $4(n=20)$ (Graph 3). 
The level of ambulation of the patients is shown in graph 4. In the preoperative phase, most patients found themselves as community walkers without assistance followed by home walkers without assistance. After the intervention, the majority of patients became home walkers with assistance, followed by community walkers without assistance and community walkers with assistance.

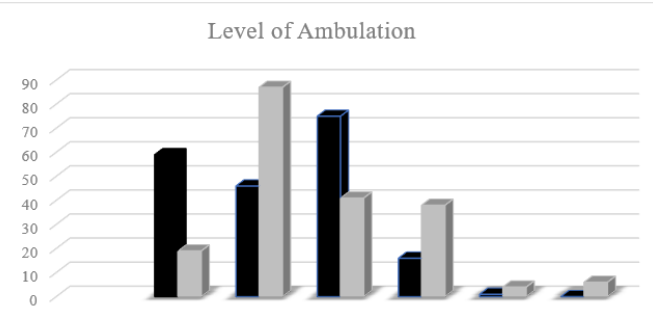

Graph 4: Level of ambulation. Source: Survey data.

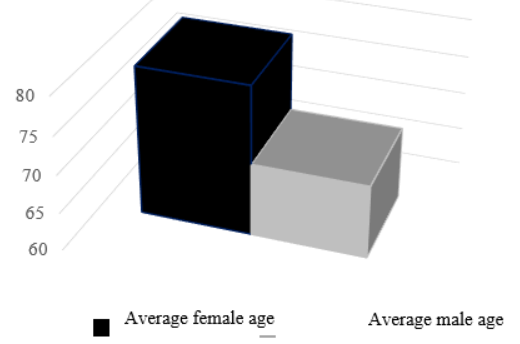

Graph 2: Age. Source: Survey data.

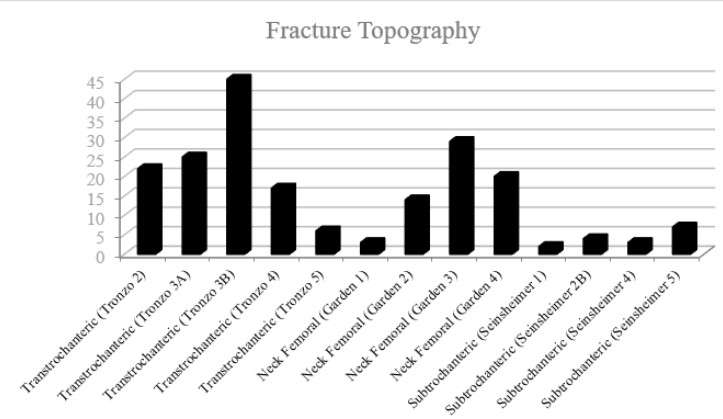

Graph 3: Fracture topography. Source: Survey data.

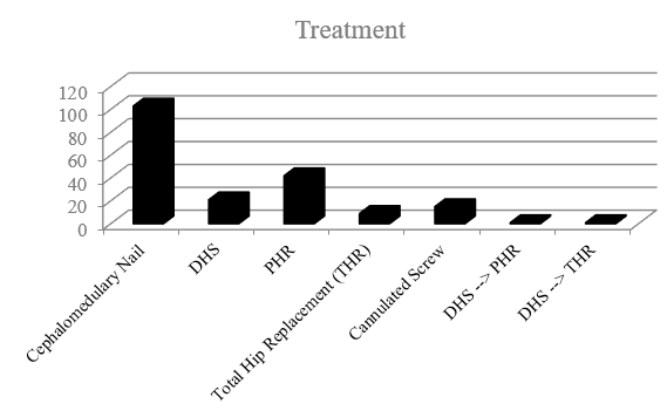

Graph 5: Treatment. Source: Survey data.
In the present study, the most prevalent comorbidities in patients who underwent PFF was Systemic Arterial Hypertension, with heart disease, chronic obstructive pulmonary disease, stroke,

Based on the data collected, it is evident that the most used treatment was the Cephalomedullary Nail, as seen in graph 5 , followed by the Partial Hip Replacement (PHR) and the Dynamic Hip Screw (DHS). 
diabetes mellitus, hypothyroidism, depression, obesity, dyslipidemias, senile dementia and Alzheimer's disease also being reported.

\section{Discussion}

The number of hip fractures that occur in the world was estimated at 1.66 million in the year 1990, with an increase forecast to 6.26 million by the year 2050 [20]. The incidence of PFF is constantly increasing due to demographic changes and the continuous increase in the average life span of the population and, therefore, the presence of a greater number of elderly patients [21].

The study data showed that most patients who suffered PFF were female, with an average age of 76 years, which denotes a high level of involvement of elderly patients. Taylor., et al. [22] revealed in their prospective study that bone mineral density of the hip was the factor most strongly associated with osteoporotic hip fracture in white and elderly women, followed by other factors such as history of previous fracture, maternal history of fracture, speed slower walking and nulliparity.

In this study, after treatment, the majority of patients became home walkers with assistance. According to Hagino., et al. [23] analyzing several predictive factors for the degree of ambulation after hospital discharge, those that significantly affected the ability to walk were age, degree of dementia, anemia, hydroelectrolytic abnormalities, abnormal chest X-ray and the presence of some disease chronic systemic.

In the present study, the death of six patients in the postoperative period was verified, which is consistent with a percentage of $3.1 \%$. Sakaki., et al. [24] reported a rate of $5.5 \%$ in their study, whereas Pereira., et al. [25] reported 8.9\% and Ricci., et al. [26] reported $5.45 \%$, all of which were carried out in different Brazilian states. However, Bentler., et al. [27] studying the population in the United States found a rate of $2.7 \%$. All authors reported that the type of fracture, the age of the patient, the number of comorbidities and the type of treatment did not influence the hospital mortality rate.

In this research, the primary treatment of choice was the Cephalomedulary Nail. The best treatment for these fractures remains controversial, as several studies comparing intramedullary and extramedullary devices show different results. O'Brien., et al. [28] in their randomized and prospective clinical trial, followed a sample of 102 patients with transtrochanteric fracture, after surgical intervention of the fracture, being 49 treated with DHS and 53 treated with the Cephalomedullary Nail. As a result, no significant difference was observed between the two groups. DHS was associated with a lower risk of postoperative complications.

The goal of PFF treatment is aimed at preventing the progression of disability and the restoration of pre-fracture function, thus making rehabilitation and care therapy necessary. Cameron., et al. [29] reports that mortality rates for hospitalized patients with hip fractures are impressive and vary between 12 and $24 \%$ in 12 months after the fracture.

In the present study, it was found that the most common comorbidity was Systemic Arterial Hypertension (SAH) in patients undergoing PFF, and heart disease, stroke, diabetes mellitus, hypothyroidism, depression and obesity, among others, were also reported. Due to the high average age of the patients, the onset of SAH found in the study, can be understood as a consequence of the increased prevalence of this condition observed with increasing age. A study by Zaitune., et al. [30] estimated that $50.4 \%$ of patients aged between 60 and 69 years old suffer from hypertension, increasing the incidence to $54.1 \%$ in the age group of 70 to 79 years old. The presence of SAH is considered a risk factor for the occurrence of falls and fractures in the elderly and may be due to the type of antihypertensive medication used by these patients. Butt [31] in his study reports that elderly patients on antihypertensive therapy had a $43 \%$ increase in the risk of hip fractures in the first 45 days of treatment initiation, which was significant for those using Beta-Blockers and Angiotensin Converting Enzyme Inhibitors (ACE Inhibitors). In patients using Calcium Channel Blockers, due to the increased excretion of this mineral, there is a contributing factor to bone fragility and consequent fractures.

Diabetes mellitus was the second most prevalent comorbidity in the present study. Ariyoshi [32] reported that the most prevalent chronic diseases in the study population with fracture of the femur in a São Paulo hospital were SAH and diabetes, respectively. The author reports that diabetes mellitus can be understood as a risk factor for fractures, due to its secondary systemic effects, such as polyneuropathy, retinopathy, vestibular dysfunction and cognitive deficit, in addition to episodes of hypoglycemia that can be triggered by the use of insulin. 
Depression, a comorbidity also found in this study, was reported as an important cause for falls and consequent fractures. Jahana and Diogo [33] believe that psychiatric disorders can lead to a high risk of falls among elderly patients due to the use of antidepressant and sedative medications. In addition, depression can lead to greater physical decline, decreased self-reliance, indifference to the environment, seclusion and inactivity, which contribute to the occurrence of trauma, as well as fractures. The fear of falling again after the occurrence of PFF, added to the loss of post-fall independence, may favor the depressive condition in the affected population.

\section{Conclusion}

The present study made it possible to add knowledge about the epidemiology of proximal femur fractures to students and health professionals, informing them about the profile of the patient susceptible to this trauma, especially at the regional level, enabling intervention actions to be carried out for avoid fracture or minimize its risks, acting in the improvement of the individual's healthdisease process.

\section{Bibliography}

1. Daniachi Daniel., et al. "Epidemiology of fractures of the proximal third of the femur in elderly patients". Revista Brasileira de Ortopedia 50.4 (2015): 371-377.

2. Franco Léo Graciolli., et al. "Factors associated with mortality among elderly people hospitalized due to femoral fractures". Revista Brasileira de Ortopedia 51.5 (2016): 509-514.

3. World Health Organization., et al. Envelhecimento ativo: uma política de saúde (2005).

4. Radominski, Sebastião Cezar., et al. "Diretrizes brasileiras para o diagnóstico e tratamento da osteoporose em mulheres na pós-menopausa". Revista Brasileira de Reumatologia 57 (2017): 452-466.

5. Silva João., et al. "Tendências Epidemiológicas das Fraturas do Fémur Proximal na População Idosa em Portugal”. Acta Medica Portuguesa 31.10 (2018).

6. Nascimento Janaína Santos. "TAVARES, Darlene Mara dos Santos. Prevalência e fatores associados a quedas em idosos”. Texto and Contexto-Enfermagem 25.2 (2016).
7. Santana Danielle Ferreira., et al. "Perfil funcional, sociodemográfico e epidemiológico de idosos hospitalizados por fratura proximal de femur". Revista Kairós: Gerontologia 18.1 (2015): 217-234.

8. Guerra Marcelo Teodoro Ezequiel., et al. "One-year mortality of elderly patients with hip fracture surgically treated at a hospital in Southern Brazil". Revista Brasileira de Ortopedia 52.1 (2017): 17-23.

9. Pinto Igor Pellucci., et al. "Does Early Surgical Fixation of Proximal Femoral Fractures in Elderly Patients Affect Mortality Rates?" Revista Brasileira de Ortopedia 54.4 (2019): 392.

10. Yamamoto Flávia Tiemi., et al. "Perfil epidemiológico de idosos submetidos à cirurgia de fratura de fêmur proximal em hospital escola na cidade de Marília, SP". Revista Brasileira de Ciências do Envelhecimento Humano 12.2 (2015).

11. Da Cunha., et al. "Fratura de quadril em idosos: tempo de abordagem cirúrgica e sua associação quanto a delirium e infecção". Acta Ortopédica Brasileira 16.3 (2008): 173-176.

12. Fahad Shah., et al. "Primary Proximal femur replacement for unstable osteoporotic intertrochanteric and subtrochanteric fractures in the elderly: A retrospective case series". Annals of Medicine and Surgery 44 (2019): 94-97.

13. Farias Fatima Izabel Dornelles., et al. "Avaliação da efetividade de um programa de atenção ao idoso com fratura de quadril: uma estratégia de rede". Revista Brasileira de Geriatria e Gerontologia 20.5 (2017): 705-716.

14. Carneiro Mariana Barquet., et al. "Fisioterapia no pós-operatório de fratura proximal do fêmur em idosos. Revisão da literature”. Acta Ortopédica Brasileira 21.3 (2013): 175-178.

15. Binder Ellen F., et al. "Effects of extended outpatient rehabilitation after hip fracture: a randomized controlled trial". JAMA: The Journal of the American Medical Association 292.7 (2004): 837-846.

16. Mesquita, Gerardo Vasconcelos., et al. "Morbimortalidade em idosos por fratura proximal do femur". Texto and Contexto - Enfermagem 18.1 (2009): 67-73. 
17. Souza, Rômulo Cristovão De., et al. "Aplicação de medidas de ajuste de risco para a mortalidade após fratura proximal de femur". Revista de Saúde Pública 41 (2007): 625-631.

18. Fernandes Roberta Arinelli., et al. "Fraturas do fêmur proximal no idoso: estudo de custo da doença sob a perspectiva de um hospital público no Rio de Janeiro, Brasil. Physis: Revista de Saúde Coletiva 21.2 (2011): 395-416.

19. Loures Fabiano Bolpato., et al. "Custo-efetividade do tratamento cirúrgico da fratura do quadril em idosos no Brasil". Revista Brasileira de Ortopedia 50.1 (2015): 38-42.

20. Cooper C., et al. "III Hip fractures in the elderly: a world-wide projection". Osteoporos International 2 (1992): 285-289.

21. OECD. Rielaborazione the European House-Ambrosetti su dati OECD Demographic and Labour Force database (2006).

22. Taylor Brent C., et al. "Long-term prediction of incident hip fracture risk in elderly white women: study of osteoporotic fractures". Journal of the American Geriatrics Society 52.9 (2004): 1479-1486.

23. Hagino Tetsuo., et al. "Prediction of ambulation prognosis in the elderly after hip fracture". International Orthopaedics 30.5 (2006): 315-319.

24. Sakaki MH., et al. "Estudo da mortalidade na fratura do fêmur proximal em idosos". Acta Ortopedica Brasileira 12.4 (2004): 242-249.

25. Pereira SR., et al. "The impact of prefracture and hip fracture characteristics on mortality in older persons in Brazil". Clinical Orthopedic Relator Research 468.7 (2010): 1869-1883.

26. Ricci G., et al. "Avaliação da taxa de mortalidade em um ano ap6s fratura do quadril e fatores relacionados à diminuição da sobrevida no idoso". Revista Brasileira de Ortopedia 47.3 (2012): 304-309.

27. Bentler SE., et al. "The aftermath of hip fracture: discharge placement, functional status change, and mortality". American Journal of Epidemiology 170.10 (2009): 1290-1299.

28. O'brien Peter J., et al. "Fixation of intertrochanteric hip fractures: gamma nail versus dynamic hip screw. A randomized, prospective study". Canadian Journal of Surgery. Journal Canadien de Chirurgie 38.6 (1995): 516-520.

29. Cameron ID., et al. "Co-ordinated multidisciplinary approaches for inpatient rehabilitation of older patients with proximal femoral fractures (Cochrane Review)". The Cochrane Library 4 (2001).

30. Zaitune MPA., et al. "Hipertensão arterial em idosos: prevalência, fatores associados e práticas de controle no Município de Campinas, São Paulo, Brasil”. Cadernos de Saúde Pública 22.2 (2006): 285-294.

31. Butt DA., et al. "The risk of hip fracture after initiating antihypertensive drugs in the elderly". Archives International Medicine 172.22 (2012): 1739-1744.

32. Ariyoshi AF. "Características epidemiológicas das fraturas de fêmur proximal tratadas na Santa Casa de Misericórdia de Batatais. São Paulo: Universidade de São Paulo". Faculdade de Medicina de Ribeirão Preto (2013).

33. Jahana KO and Diogo MJDE. "Quedas em idosos: principais causas e consequências”. Saúde Coletiva 4.17 (2007): 148-153.

\section{Volume 4 Issue 9 September 2021}

(C) All rights are reserved by Edir Soccol Junior., et al. 